\title{
Coparentalidade e união estável: Diferenças e requisitos à luz do caso Gugu Liberato
}

\author{
Coparenting and stable union: Differences and requirements in light of the Gugu Liberato case \\ Coparentalidad y unión estable: Diferencias y requisitos a la luz del caso Gugu Liberato
}

Recebido: 29/06/2021 | Revisado: 05/07/2021 | Aceito: 10/07/2021 | Publicado: 21/07/2021

\author{
Milena Ximendes dos Reis \\ ORCID: https://orcid.org/0000-0002-7580-3604 \\ Christus Faculdade do Piauí, Brasil \\ E-mail:milenaxmds@gmail.com \\ Naira Kelly Borges de Andrade \\ ORCID: https://orcid.org/0000-0002-6421-5188 \\ Christus Faculdade do Piauí, Brasil \\ E-mail: nairakellyborgesdeandrade@gmail.com \\ Ivonalda Brito de Almeida Morais \\ ORCID: https://orcid.org/0000-0002-1306-7568 \\ Christus Faculdade do Piauí, Brasil \\ E-mail: ivonaldaa@yahoo.com.br \\ Genyvana Criscya Garcia Carvalho \\ ORCID: https://orcid.org/0000-0002-8151-8746 \\ Christus Faculdade do Piauí, Brasil \\ E-mail: genyvanacarvalho@icloud.com
}

\begin{abstract}
Resumo
Essa pesquisa traz como tema "Coparentalidade e União Estável: diferenças e requisitos à luz do caso Gugu Liberato", tendo como objetivo geral analisar o instituto da coparentalidade no Brasil e suas distinções com a união estável, trazendo como lição o caso do apresentador Gugu Liberato. Os objetivos específicos do estudo são: conceituar o instituto da coparentalidade à luz do ordenamento jurídico brasileiro; diferenciar a coparentalidade da união estável; apontar os problemas que podem ocorrer mediante as novas realidades multiparentais e examinar as divergências existentes no caso midiático do apresentador Gugu Liberato. A metodologia aplicada foi a pesquisa bibliográfica, tendo como fonte livros, site IBDFAM, a legislação vigente, decisões jurisprudenciais referentes ao tema objeto do estudo e busca de artigos nas principais bases de dados, como Google acadêmico e Periódicos da Capes. Foram utilizados como descritores para a pesquisa: coparentalidade, união estável, Gugu Liberato e Direito de Família, tendo como principais autores, Rodrigo da Cunha Pereira, Cristiano Chaves Farias, Maria Berenice Dias, Pablo Stolze, dentre outros. Ao final, conclui-se que a distinção da família coparental da família convivencial, no caso concreto, pode não ser uma tarefa fácil para o julgador. No entanto, há que se analisar se estão presentes ou não os requisitos da união estável e, por fim, observar a existência de contrato de coparentalidade, disciplinando a relação ali existente, principalmente em relação à responsabilidade de cada um com a prole.
\end{abstract}

Palavras-chave: Direito de família; Coparentalidade; União estável; Gugu Liberato.

\begin{abstract}
The theme of this research is "Coparenting and Stable Marriage: differences and requirements in the light of the Gugu Liberato case", with the general objective of analyzing the institute of coparenting in Brazil and its distinctions with the stable union, bringing as a lesson the case of presenter Gugu Liberato . The specific objectives of the study are: to conceptualize the institute of coparenting in the light of the Brazilian legal system; differentiate coparenting from stable union; point out the problems that may occur due to the new multiparental realities and examine the existing differences in the media case of presenter Gugu Liberato. The methodology applied was bibliographic research, having as source books, the IBDFAM website, current legislation, jurisprudential decisions regarding the subject of study and search for articles in the main databases, such as Google Academic and Capes Periodicals. The following were used as descriptors for the research: coparenting, stable union, Gugu Liberato and Family Law, with the main authors being Rodrigo da Cunha Pereira, Cristiano Chaves Farias, Maria Berenice Dias, Pablo Stolze, among others. In the end, it is concluded that the distinction of the coparental family from the coexistence family, in the specific case, may not be an easy task for the judge. However, it is necessary to analyze whether or not the requirements of a common-law marriage are present and, finally, to observe the existence of a co-parenting contract, disciplining the existing relationship, mainly in relation to the responsibility of each one with the offspring.
\end{abstract}

Keywords: Family law; Coparenting; Stable union; Gugu Liberato. 


\begin{abstract}
Resumen
El tema de esta investigación es "Coparentalidad y matrimonio estable: diferencias y requerimientos a la luz del caso Gugu Liberato", con el objetivo general de analizar el instituto de coparentalidad en Brasil y sus distinciones con la unión estable, trayendo como un lección el caso del presentador Gugu Liberato. Los objetivos específicos del estudio son: conceptualizar el instituto de coparentalidad a la luz del sistema legal brasileño; diferenciar la coparentalidad de la unión estable; señalar los problemas que pueden surgir debido a las nuevas realidades multiparentales y examinar las diferencias existentes en el caso mediático del presentador Gugu Liberato. La metodología aplicada fue la investigación bibliográfica, teniendo como fuente los libros, el sitio web del IBDFAM, la legislación vigente, las decisiones jurisprudenciales sobre el tema de estudio y la búsqueda de artículos en las principales bases de datos, como Google Academic y Capes Periodicals. Para la investigación se utilizaron los siguientes descriptores: coparentalidad, unión estable, Gugu Liberato y Derecho de familia, siendo los autores principales Rodrigo da Cunha Pereira, Cristiano Chaves Farias, Maria Berenice Dias, Pablo Stolze, entre otros. Al final, se concluye que la distinción de la familia coparental de la familia de convivencia, en el caso concreto, puede no ser una tarea fácil para el juez. Sin embargo, es necesario analizar si se cumplen o no los requisitos de una unión estable y, finalmente, observar la existencia de un contrato de coparentalidad, disciplinando la relación existente, principalmente en relación a la responsabilidad de cada uno con la descendencia.
\end{abstract}

Palabras clave: Derecho de família; Coparentalidad; Unión estable; Gugu Liberato.

\title{
1. Introdução
}

As metamorfoses sociais e as modificações comportamentais, existentes nas relações humanas, atingem o Direito de Família que está em contínua transformação. Manifestação disso são os diversos modelos de famílias existentes, como um reflexo dessa realidade social.

A história da humanidade não é algo inerte, passa por grandes modificações ao longo do tempo, sendo um processo dinâmico. Ao longo da trajetória humana, a ciência e a tecnologia foram bem sucedidas, ao tratar de problemas biológicos, reprodutivos e sociais. Foi esse avanço da ciência e tecnologia que colocou em foco a necessidade de uma nova estruturação no Direito de Família.

Segundo Nader (2016), a chegada dos métodos contraceptivos e os seus efeitos, o descobrimento do DNA bem como a fertilização in vitro, impulsionaram grandes mudanças para o Direito, decorrentes dos acontecimentos científicos e tecnológicos. Tais acontecimentos foram importantes para que houvesse a separação do exercício da sexualidade com a multiplicação da espécie. Além disso, com o advento da Carta Magna de 1988 e o Código Civil de 2002, muitos modelos familiares passaram a ser reconhecidos pelo ordenamento jurídico brasileiro, como a família monoparental e a união estável bem como os filhos havidos ou não do matrimônio.

Nos dias que correm, com a repercussão midiática envolvendo a morte do apresentador de televisão Gugu Liberato, mais dois institutos do Direito de Família passaram a aderir ao vocábulo brasileiro: a Coparentalidade e a União Estável.

Esse estudo, portanto, traz como tema: Coparentalidade e União Estável: diferenças e requisitos à luz do caso Gugu Liberato, tendo como objetivo geral analisar o instituto da coparentalidade no Brasil e suas distinções com a união estável, trazendo à baila o caso do apresentador Gugu Liberato, que causou grande comoção em toda a sociedade, suscitando inúmeros questionamentos que envolvem intrinsecamente o ramo jurídico, especialmente o Direito de Família e o Direito das Sucessões, clamando por respostas que direcionem a uma resolução justa para ambas as partes.

Os objetivos específicos do estudo são: conceituar o instituto da coparentalidade à luz do ordenamento jurídico brasileiro; diferenciar a coparentalidade da união estável; apontar os problemas que podem ocorrer mediante as novas realidades multiparentais e examinar as divergências existentes no caso midiático do apresentador Gugu Liberato.

Em relação ao apresentador Gugu Liberato, existia um contrato de coparentalidade assinado em 2011 pelas partes. No entanto, Rose Miriam Di Matteo, contesta na justiça a veracidade do mesmo, alegando ainda que era companheira de Gugu e que o contrato ocorreu em um momento de crise do casal. Sob esse contexto, surge o questionamento: Como demostrar a existência de uma família coparental no Brasil quando ela estiver em conflito com outros institutos, como o da União Estável? 
Nessa esteira, pode-se perceber uma linha tênue ao diferenciar o instituto da Coparentalidade com o da União estável. É necessário um conhecimento mais aprofundado, ficando difícil a distinção para quem se encontra fora da relação.

Diante de toda essa discussão, faz-se necessária uma abordagem jurídica que busque uma melhor compreensão de todos os pontos que envolvem o caso. O primeiro questionamento se refere ao conceito de família, se existe ou não uma união estável e o que seria um contrato de coparentalidade e seus reflexos para o Direito.

Para contextualizar as novas facetas que englobam o direito de família, faz-se mister contemplar o segundo capítulo com uma abordagem acerca da evolução histórica do Direito de Família com a chegada da Constituição de 1988 e o Código Civil de 2002. Tais legislações foram mola propulsora para que novos arranjos familiares pudessem ter os seus direitos amparados com base na função social da família que hoje é o afeto. Ademais, alguns princípios fazem parte dessa importante evolução do Direito, como o princípio da dignidade da pessoa humana, afetividade e solidariedade.

\section{Família: Alguns Princípios e Função Social}

A família é comum a todas as sociedades e está presente na maioria das culturas, sendo que cada sistema familiar é regido pelas normas próprias impostas por cada organização social. Ao fazer um estudo histórico da humanidade, é perceptível que a família é vista como uma organização bem antiga, sendo anterior ao Direito e ao Estado e de suma importância para a formação humana.

Nos modelos de família da Antiguidade, era visto que o princípio da autoridade recaia sobre o instituto familiar e na maioria dos casos era exercido pela figura masculina, denominando assim o que hoje entendemos como patriarcalismo.

$\mathrm{Na}$ família patriarcal, o homem prevalece sobre os demais membros da família, exercendo o seu poder sobre todos. Segundo Pereira (2019), o pai era ao mesmo tempo o chefe político e o juiz que comandava todos os membros da família. Exercia sobre os filhos o direito de vida e morte, podendo até mesmo impor pena corporal sobre eles.

O Direito de Família é um dos ramos do Direito que mais sofrem modificações. Essas mudanças estão diretamente ligadas ao enfraquecimento do modelo patriarcal, que por sua vez está vinculado a todo um contexto histórico que vem desde a Revolução Industrial até os dias atuais. A partir dessa nova visão sobre o patriarcalismo começam a surgir movimentos feministas, o que gera uma grande revolução e uma nova visão sobre a família.

Diante dessas transformações, principalmente nos costumes e na liberdade sexual, começou-se a imaginar que a família entraria em crise, causando uma grande desordem. Em um processo histórico, é normal o surgimento de várias indagações e inquietações, dentre elas pergunta-se como organizar juridicamente a família, já que não há mais um único modelo familiar, e sim uma pluralidade? A família deixou de ter uma única forma e passou contemplar as inúmeras possiblidades de formação familiar.

A visão de família nos dias atuais é mais ampla, está em constante movimento e adequação social, desenvolvendo-se para atender os anseios sociais. Assim, a árvore genealógica ganhou mais galhos estando todos interligados, independente de laços sanguíneos. O modelo atual de família está pautado na pluralidade, reciprocidade, na busca pela felicidade e progresso dos membros. Logo, pensamentos individualistas não são mais válidos. A composição da família deixou de ser essencialmente um núcleo econômico e de reprodução, sendo o afeto e o respeito a base dos modelos recentes.

Nesse contexto, após diversas tentativas surge a Lei do Divórcio, aprovada no Brasil em 1977. A partir daí, os casais poderiam ter a liberdade em escolher se continuariam casados ou não. Nenhum dos participantes da relação estaria obrigado a continuar casado mesmo estando infeliz na relação, o que possibilitou aos cônjuges, a dissolução do vínculo matrimonial, antes visto como indissolúvel, abrindo espaço para a formação de novos relacionamentos e a construção de uma nova família, compreendendo-se que os filhos poderiam crescer sem traumas mesmo com os pais separados, já que eles estariam melhores ao ver seus pais mais felizes. 
Com a Constituição Federal de 1988, as grandes evoluções são consolidadas. Sem dúvida, a principal conquista gira em torno do reconhecimento da igualdade de direitos entre homem e mulher, sendo ambos sujeitos de direto. Os princípios fundamentais também ficaram conhecidos para o ordenamento jurídico brasileiro, sendo um grande marco para o Direito de Família, trazendo uma nova roupagem, pois foi a partir da revolução constitucional que surgiram os princípios fundamentais para a organização jurídica da família.

O Direito de Família precisou deixar para trás definitivamente antigos pensamentos, como o da ilegitimidade dos filhos, já que todos os modelos de filiação foram amparados pelo Estado e a visão deturpada da relação, pela qual o homem era superior a mulher e o casamento visto como único modelo de constituição familiar.

A carta constitucional define a família como a base da sociedade, garantindo proteção especial, mas diferente do que ocorreu nas constituições anteriores, a Constituição de 88 não traz um único modelo de família. Sobre o tema, Dimas Messias de Carvalho (2020) comenta que a Constituição Federal, ao trazer o princípio da liberdade como base para o planejamento familiar, alarga o conceito de família, mostrando que não ocorre mais somente o modelo pautado no casamento, ou pela filiação biológica.

A família atual se constitui pela convivência socioafetiva e na vontade recíproca dos seus membros de formar uma família, de traçar seus sonhos em comum independente de qualquer ato formal. Para Maria Berenice Dias (2021), a família é norteada pelo princípio da afetividade. O que se percebe é a evolução do que se entende por família, nasce uma preocupação com os sentimentos, com interesses afetivos no lugar de função hierárquica ou patriarcal.

Convém destacar, resumidamente, os princípios fundamentais da Constituição que norteiam as relações sociais, bem como a função social: Princípio de proteção da dignidade da pessoa humana (É considerado o princípio máximo, desempenha papel de cláusula pétrea, a fim de confirmar os valores e segurança jurídica defendidos pela Carta política; Princípio da solidariedade familiar (a família deve ser construída tendo como base a solidariedade de seus membros); Função social da família (a família é considerada a base da sociedade, sendo responsável pela formação do indivíduo); Princípio da afetividade nas relações familiares (a afetividade é vista como um traço da família atual, sendo de suma importância o respeito, que deverá se fazer presente em todos os membros familiares).

\section{União Estável}

A Constituição Federal traz uma especial proteção da família, inclusive aquelas que não advêm de um casamento, deixando claro a sua importância na dignidade da pessoa humana. Nesse sentido, essa proteção garante que o núcleo familiar resguarde todos os seus direitos.

Atualmente, verifica-se que as relações familiares são pautadas na afetividade e não no que disciplina o legislador, pois não é ele quem cria a família, mas sim a família que impulsiona o legislador a criar as leis conforme a sua evolução. A união estável, nem sempre foi reconhecida e esse reconhecimento foi postergado pelo legislador por muito tempo, haja vista que houve um longo processo até se chegar aos dias atuais. É preciso ressaltar que o Código Civil de 1916 só reconhecia e valorizava a família matrimonial, vista como uma instituição que objetivava a construção de patrimônio e a criação da prole.

No passado, antes de 1977, com a lei do divórcio, Lei No 6.515/77 (Brasil, 1977), o casamento era considerado indissolúvel, uma vez que não se conseguia desvencilhar-se do outro, mesmo que aquela relação não prosperasse.

As famílias que se separavam antes desta lei e optavam por constituir outra vida, acabavam por sofrer diversas oposições em virtude dessas uniões que ocorriam de fato e não tinham como serem formalizadas, sendo denominadas de "concubinato", um tipo de família que não era valorizada pelo legislador que possuía uma mentalidade obsoleta.

Observou-se que mesmo aquelas pessoas separadas poderiam ter o resguardo da lei. Contudo, só houve uma grande evolução com a chegada da Carta Magna de 1988 (Brasil, 1988), que deu aceitabilidade a famílias que viviam fora do casamento. 
Muitas vezes aquelas famílias não possuíam impedimentos, mas optavam por não se casar, apenas convivendo, semelhante a uma família matrimonial, mesmo não sendo.

A Constituição Federal trouxe no art. 226, $\S 3^{\circ}$ (Brasil, 1988) o amparo e direito dessas pessoas sendo contempladas como um novo modelo familiar. A União Estável veio para sustentar o concubinato puro, aquele caracterizado pela união de duas pessoas que não possuíam impedimentos.

Mais uma gigantesca modificação do Direito de família foi o Código Civil de 2002 (Brasil, 2002), que viabilizou um livro exclusivamente para devotar-se acerca da União Estável no Brasil, nos arts, 1.723 a 1.727, que efetivamente regulamentou com normas e regras caracterizadoras da União estável trazendo mais segurança para sua formação.

É notável a semelhança entre o casamento e a união estável. Ambos os institutos são formados com base na comunhão de afeto entre os envolvidos da relação familiar e suas diferenças consistem no fato do matrimônio ter início com a aprovação do Estado. Enquanto a união estável necessita basicamente da convivência e da consolidação do comprometimento, inexistindo formalidade para seu surgimento. A união estável, apesar de dispensar as formalidades exigidas no casamento, começa a se caracterizar pela vontade de vida em comum. Torna-se necessário o consenso de ambos os participantes da relação, podendo este surgir conforme a evolução do relacionamento.

Nesse sentido, para que se forme a união estável, é importante que exista a concreta criação de família e não um simples anseio futuro para formá-la como existe no namoro e com os esponsais. É a união estável uma exteriorização palpável como se dá no casamento, que se caracteriza pela comunhão de vida estável.

É importante salientar que a União Estável não foge das obrigações de um matrimonio, pois está condicionada aos impedimentos absolutos do casamento civil, que foram elencados no Art. 1.521 do Código Civil de 2002 (BRASIL,2002). Entretanto, no que se refere à pessoa divorciada, esta não se enquadra no rol de impedidos, podendo estabelecer uma união estável. De acordo com Flávio Tartuce (2020), é consistente a correlação da união estável ao casamento para o Direito de Família, do mesmo modo trazido pelo Novo CPC.

Nesse contexto, alguns são os requisitos para que se caracterize a União estável segundo o legislador. Dentre eles, podese citar a duração, publicidade, continuidade e o desígnio de composição familiar.

Ademais, pode-se citar alguns outros exemplos que podem configurar uma união estável, como a presença de uma prole, a construção patrimonial em conjunto e a coabitação que já não pode ser considerada como requisito ensejador da união estável, tendo em vista que muitos casais estão vivendo sob diferentes residências.

É dispensável o tempo mínimo de convivência e habitação debaixo do mesmo teto. Porém não dispensa os requisitos mencionados anteriormente, para conceder identificação como núcleo familiar que é a convivência duradoura e pública, com notoriedade e continuidade, apoio mútuo ou assistência mútua, deveres de guarda, sustento e educação dos filhos bem como lealdade e respeito.

Esses elementos são passíveis de enormes controvérsias, haja vista que muito se questiona a essencialidade de coabitação, prole comum dentre outros elementos. É sabido que para que haja um casamento há a necessidade bem como a celebração do negócio jurídico. Contudo, na união estável não há esse elemento pois esta perpetra-se a partir das relações de vida.

No entendimento de Nader (2020), diferentemente do casamento que ocorre um negócio jurídico solene, a união estável possui como característica a informalidade, o que torna difícil a sua comprovação de existência pela falta de uma escritura probatória.

Para que a união estável seja reconhecida, ela há de persistir no tempo, demonstrando que aquela relação tenha se configurado e solidificado como se casados fossem. Deve haver o intuito de constituição de gerar uma família, tendo o vínculo 
formado entre as partes como qualquer outra família, podendo vir a ter filhos ou não, tendo uma relação que transcende o namoro que se projeta uma vida comum futura, dar um passo a mais no relacionamento.

Na união estável, já se configurou a união familiar, podendo vir ou não a formalização do casamento no futuro, sendo desnecessário para o reconhecimento da relação como união estável. Na prática, verifica-se que a maior parte dos companheiros vivem juntos e dividem despesas, conjugam os projetos e os mesmos interesses embora haja a súmula que dispensa a coabitação.

Uma prerrogativa da união estável é que o casal pode eleger o regime de bens mais adequado aos seus interesses e também trazer algumas cláusulas para esse relacionamento, sendo denominado como contrato de convivência.

A união estável carrega direitos e deveres resultantes desse modelo familiar, trazendo o dever de lealdade que não será equivalente ao dever de fidelidade que é somente inerente ao casamento. O Código Civil (BRASIL, 2002) preceitua, via de regra, que, no silêncio das partes, aplica-se o regime da comunhão parcial de bens que quer dizer que todos os bens adquiridos durante a união estável devem ser partilhados independentemente de esforço comum, mas os bens adquiridos a título de doação ou herança não serão partilhados bem como aqueles percebidos antes da união.

É plenamente aceitável o requerimento de alimentos perante o companheiro. No entanto, cessa a obrigação do pagamento de alimentos se o companheiro que pleiteia vier a casar, constituir união estável ou concubinato ou se tiver algum comportamento indigno perante aquele que estiver pagando os alimentos. Tais hipóteses não se aplicam àquele companheiro que paga os alimentos e vem a se casar.

\section{Coparentalidade}

A família deve ser compreendida como a primeira instituição social que o ser humano faz parte. Nela, está presente um misto de fatores e é onde são desenvolvidas as primeiras relações sociais. Ao mesmo tempo, é em meio à família que acontecem as grandes realizações da vida humana. É notório que a família é de suma importância para o desenvolvimento e realização de todos os âmbitos da vida. Além disso, a família assume diferentes funções e essas estão relacionadas aos diferentes valores empregados por cada sociedade.

Diante das inúmeras formas de construção familiar, é necessário saber que existem pessoas que possuem o grande sonho de casar e através do casamento declaram a vontade de formar uma relação conjugal. Outras apenas possuem o desejo de ter filhos, sem a necessidade de vínculo conjugal ou sexual. Isso não quer dizer que não haverá qualquer comunicação entre as partes envolvidas, nem tão pouco que essa circunstância seja fator que impeça a formação de vínculos duradouros, que perdurem por mais tempo, até mesmo do que um casamento ou união estável. Isso se dá pelo fato dessas pessoas possuírem o dever de cuidar, criar e educar uma criança até o momento em que ela se torne independente. A partir desse entendimento, observa-se um novo modelo de formação familiar, no qual é dado o nome de coparentalidade.

O instituto da coparentalidade, discutido e analisado dentro os novos arranjos familiares da contemporaneidade, é pautado nesse modelo de família que possui como base assim como os outros modelos familiares, o afeto.

Dessa maneira, como lecionam Farias e Rosenvald (2021), a família eudemonista existe por causa dos seus componentes e não estes em função da simples estrutura familiar, buscando a felicidade pessoal e solidária de cada um de seus membros, redirecionando o eixo do direito para a proteção da pessoa humana dentro das relações sociais, que antes era voltado apenas à manutenção da instituição social por si só.

A coparentalidade é vista como uma parceria. Não é apenas querer ter filhos. É cria-los juntamente com o genitor. É compartilhar os cuidados, a educação, o acompanhamento, o amor e a educação. É notável que nesse sentido, há uma figura paterna e materna, o que não há é o laço romântico que une o casal, pois ambos estão juntos, não como companheiros no amor, mas sim como companheiros na criação dos filhos. 
Nas palavras de Pereira (2019), em um contexto histórico, “o Direito de Família sempre foi determinado por uma moral sexual", e esse pensamento ainda está muito presente na atualidade. Isso tudo porque até meados da década de 1980, a mulher só podia ter relações com o seu marido. Se essa tivesse relações extraconjugais seria punida em não ter o direito na guarda dos filhos, do preconceito social.

Com o passar do tempo, por volta da década 1990, surge um novo pensamento, mais moderno e condizente com a sociedade do momento. Nota-se então que nem sempre a paternidade ou maternidade são vínculos específicos das relações conjugais. Ambas as funções podem ocorrer sem de fato evidenciar uma ligação amorosa entre homem e mulher.

A coparentalidade é modelo de família no qual se vive a sexualidade sem a fecundidade. A sexualidade sem o amor conjugal. A fecundidade sem a sexualidade, traduzindo-se, na prática, a ruptura com o matrimônio concebido no entrelaçamento de amor, sexualidade e fecundidade. Estes três elementos se distanciam, cada um percorrendo um itinerário próprio, distinto dos outros, mas com consequências muito sérias e importantes para a sociedade e para o ramo jurídico.

Grande parte da coparentalidade gira em torno de uma maternidade e paternidade biológica. No entanto, sem envolvimento amoroso entre as partes. Graças aos avanços da ciência, a reprodução está cada vez menos atrelada ao ato sexual caso assim seja o desejo dos interessados. Na maioria das vezes, o processo de geração de filhos se vale de técnicas de reprodução assistida.

Conforme Pereira (2020), existem pessoas que desejam constituir uma família com o intuito meramente voltado na criação de uma prole. Dessa maneira, há pessoas que almejam construir uma família parental, pois não desejam nenhum tipo sexualidade ou conjugalidade. Por outro lado, outras almejam apenas o casamento ou uma união estável sem o compromisso de gerar e criar filhos. Toda essa conjuntura, teve início a partir da década de 1960, com os primeiros bancos de sêmen que desvincularam o sexo como o único meio de reprodução.

Segundo Ahrons (1981), a expressão ‘coparentalidade’ foi utilizada pela primeira vez na década de 70, por Bohannan para mencionar pais divorciados que criavam os seus filhos. Contudo, a coparentalidade não existe somente em casos de divórcio, pois atualmente sua existência também decorre de pessoas que se reúnem para tão somente criar filhos, negociando suas funções e contribuindo na formação destes, mesmo que não haja um casamento. A situação de casado ou divorciado pode estar presente numa relação coparental. Porém, não é o único meio que origina a mesma, pois esta pode ser gerada, inclusive por amigos ou pessoas que não são pais biológicos de uma criança. (Mchale et. al 2004).

Como descrito por Frizzo et al. (2005), a nomenclatura coparentalidade começou a fazer parte do cotidiano das pessoas para mencionar aquelas relações decorrentes de um divórcio, caracterizada unicamente na criação dos filhos por aqueles genitores que já tiveram uma relação conjugal no passado.

A coparentalidade no Brasil, ainda não fora contemplada com uma legislação própria. Entretanto, existe um projeto de lei n 394, de 2017, do Senado federal, que visa alterar uma parte do ECA, (Brasil,1990).

O artigo 73, possui a proposta com a seguinte redação: "Para a adoção conjunta, os adotantes não precisam constituir entidade familiar, mas é indispensável a comprovação de que existe convivência harmônica entre eles".

Percebe-se o intuito de se enquadrar no âmbito da adoção a possibilidade de duas pessoas se comprometerem na criação de uma criança ou adolescente, firmando uma família coparental, sem que haja o vínculo matrimonial ou conjugal para isso.

Na visão de Vilas-Bôas (2018), a coparentalidade ocorre quando duas pessoas escolhem um parceiro que possui características condizentes com a sua personalidade e estilo de vida, como qualidades intelectuais e valores que são parecidos, para que assim através dessa compatibilidade, possam em conjunto, criar uma prole.

Dessa forma, o casal escolhe um meio, que geralmente é através da inseminação artificial e assim estabelecem acordos para cuidar da criança. A prole derivada de tal acordo, apresenta características positivas conforme os anseios de cada um, 
contudo não irá observar a relação conjugal, uma vez que não existe entre os genitores, que provavelmente se relacionam apenas como bons amigos.

A coparentalidade é um instituto que diz respeito a uma grande quantidade de compromissos e de atribuições, responsabilidades que se apoia em funções ajustadas entre os componentes dessa relação. As atribuições são divididas por um acordo, ou seja, tudo é negociado por ambas as partes.

Com técnicas genéticas, a conjugalidade tornou-se um processo contratualmente estabelecido para procriação de filhos. Em outra perspectiva, a coparentalidade não dependerá de vínculos afetivos.

Coparentalidade ou famílias coparentais são aquelas que se constituem entre pessoas que não necessariamente estabeleceram uma conjugalidade ou nem mesmo uma relação sexual. O que diferencia a união coparental das demais é que não há uma relação que se assemelhe ao matrimonial. No dizer de Rosa (2020), ainda que socialmente incomum, não se pode preterir esse novo modelo familiar enquanto exercício do livre planejamento como estabelece a CF de 1988.

Nessa esfera, possui como base a proteção ao interesse dos filhos, haja vista que proveniente desse pacto de vontades, ambas as partes devem observar o que preconiza a Lei 8.069/90 ECA, (Brasil, 1990) no que concerne o princípio do melhor interesse da criança e do adolescente, além de uma proteção integral para constituir um núcleo familiar.

Como caracteriza Rosa (2020), esses acordos de paternidade /maternidade têm aludido ao Direito novas espécies de pactos intitulados como "contratos de geração e filhos" que trazem alguns pressupostos para sua formação como nome do(a) filho, convivência, guarda sustento além de outros exemplos. Para que esses contratos surtam efeitos jurídicos, deve-se analisar alguns requisitos como estabelece o art. 104 do CC, (Brasil, 2002).

A coparentalidade necessita do apoio e comprometimento mútuo de ambas as partes envolvidas. É por meio dessa responsabilidade que os pais podem acordar como cada um exercerá a sua função, buscando sempre o melhor para a criança. A divisão dos papeis fica a critério dos genitores, cada um com uma função importante para o desenvolvimento pleno da criança até a vida adulta.

A família coparental pode ser constituída por qualquer pessoa, independente de condições financeira, raça ou opção sexual, na constituição desse vínculo a criança será biológica. É relevante ressaltar que podem participar dessa relação mais de um pai ou mais de uma mãe, desde que ambos ao envolvidos façam o registro do filho.

A união coparental é uma novidade no Brasil, sendo que em outros países já é uma realidade. É notório que se mudam os tempos e por conseguintes os modelos de famílias. O Direito de Família ganhou novas perspectivas de segurança constitucional, igualitárias e de pluralidade, protegendo as várias formas de estruturas socioafetivas, desvinculando o conceito de família do casamento tradicional, enfatizando os princípios da dignidade da pessoa humana, da solidariedade e do afeto como uma busca pela felicidade exercida pelos componentes da relação.

Muitos brasileiros buscam em redes sociais parceiros com o intuito de terem filhos e mesmo sendo um instituto novo, nota-se um grande crescimento da coparentalidade no Brasil, gerando assim uma grande chance da realização de um sonho para os que desejam ter filhos sem de fato ter um vínculo afetivo e conjugal.

De acordo com o que ficou demonstrado, os institutos do direito de família estão sempre se modificando e se moldando à realidade social moderna, ficando claro que existe uma grande necessidade de proteção dos novos arranjos familiares. Isso não poderia ser diferente no Brasil, já que é notável a diversidade desses modelos que estão se tornando rotineiros.

Nessa senda, surge a coparentalidade como uma nova formação familiar para as pessoas que desejam constituir uma família pautada no afeto, companheirismo e confiança, unida pela única vontade de ter e de cuidar do filho comum.

O estudo sobre a coparentalidade e o aumento de casos no Brasil, surge a partir de uma breve reflexão sobre a transformação da entidade familiar ao longo da História. A evolução da família mostra uma ruptura dos paradigmas, que influencia a sociedade e o ramo jurídico como um todo. Foi por meio de tais modificações que a Constituição da República 
incorporou mudanças sociais que impactaram todo o Direito de Família brasileiro, adotando princípios que abordam a proteção a toda e qualquer forma de família constituída pelo afeto.

Todos os modelos familiares precisam dessa proteção. Não há como esperar que em meio a uma sociedade tão complexa exista apenas um modelo familiar. Com o passar dos anos o direito se renova e a sociedade toma novos rumos.

O conceito de família se transformou e o modelo único formado pelo casamento foi substituído pela pluralidade de formas, tendo como pano de fundo a afetividade de seus membros. A coparentalidade, assim como todos os outros modelos de família, possui um ponto em comum: o afeto. O principal motivo desse instituto é a realização de um sonho de ter filhos e ainda, dividir tal responsabilidade e alegria com outra pessoa.

Muitos brasileiros estão alcançando o sonho de construir uma família, simplesmente buscando seus parceiros pelas redes sociais. Essa nova possibilidade quebra rupturas impregnadas pela tradicional parentalidade, definindo a ação de criar e instruir os filhos biológicos ou adotados, envolvendo meramente uma ligação afetiva entre os genitores sem que haja nenhum envolvimento sexual.

Existem diversos anúncios acerca da coparentalidade nos dias atuais. Nas redes sociais, grupos já foram criados unicamente com esse propósito de geração de filhos. Nessas plataformas, as pessoas interessadas apresentam-se através de um perfil que funciona como uma espécie de catálogo no qual destacam suas características e qualidades e enfatiza o intuito de ter um filho. De acordo com os critérios escolhidos por cada um, o diálogo que se inicia dali por diante pode resultar na geração de uma nova vida. (BBC NEWS Brasil, 2018).

A prática de um contrato para gerar filhos é bastante comum em alguns países como os Estados Unidos, o indivíduo que a procura, visa um parceiro sem um vínculo amoroso, por ser algo habitual. Existem plataformas oficiais que ajudam os interessados no que tange esse tema.

Por tudo que foi exposto, é notório que o conceito de família mudou em muitos aspectos. A consanguinidade e a tradicional instituição do casamento, vem perdendo espaço nas mais recentes doutrinas e jurisprudência e até mesmo pela própria norma, por dois quesitos muito mais apropriados à nova realidade: $\mathrm{o}$ afeto $\mathrm{e}$ a dignidade da pessoa humana.

Ter filhos nos dias de hoje não é mais algo restrito, voltado apenas para as pessoas que vivem no instituto do casamento. A união coparental é vista como um instituto novo que enseja a constituição de um modelo de família. Tal modelo se difere dos demais, pois traz consigo algumas características que são inerentes, tornando-se único e inovador.

Assim sendo, constitui-se entre duas pessoas do mesmo sexo ou de sexos diferentes, no intuito de ter um filho em conjunto, sem que necessariamente tenham entre si uma relação conjugal, amorosa ou sexual. Ou seja, quando ambas as pessoas buscam um mesmo objetivo: criar uma parceria para a maternidade/paternidade responsável sobre a criança, oferecendo ao filho, uma ajuda mútua, educação, amor, saúde, e constituição de valores.

A principal característica da família coparental é a preocupação com o bem- estar da criança e a ela é destinado todo o empenho e atenção dos pais, pois eles se unem com único propósito de oferecer uma convivência privilegiada a fim de proteger ao melhor interesse da criança.

A união coparental, embora não muito conhecida, não é vista como algo ilegal. Ela pode ser formalizada através de um contrato de coparentalidade, no qual serão divididos os deveres de cada um, sempre em conjunto, dividindo o poder familiar e compartilhando funções.

Essas funções não necessariamente precisam ser divididas, levando em conta um equilíbrio. Não é necessária uma equidade. Os pais dividem, observando o que de fato será melhor para a criança, o que se torna necessário e estabelece regras seguras para a convivência do filho que vai nascer contendo como requisito a garantia de direitos mínimos como: guarda, alimentos, convivência, registro civil, entre outros efeitos decorrentes da filiação. 
Os contratos estabelecidos em casos de coparentalidade têm uma grande relevância jurídica e são essenciais em situações de conflito entre os genitores, feitos especificamente com o propósito de dar segurança jurídica às partes, estabelecendo regras de convívio e, em caso de descumprimento, servirão de base para uma eventual discussão judicial.

$\mathrm{O}$ instituto da união estável sempre se fez presente na sociedade. No entanto, não era reconhecida como formação familiar. Com o passar do tempo e com as modificações sociais, foi necessária uma readequação a esse pensamento e a união estável foi ganhando o seu reconhecimento pouco a pouco. Para Maria Helena Diniz (2020), a união estável é entendida como uma relação convivencial, que é convertida em casamento caso não haja razões para impedimento, já que as causas suspensivas, não são capazes por si só de impedir a configuração e reconhecimento como entidade familiar.

Segundo Pereira (2020), o requisito da conjugalidade é o que define se duas pessoas possuem uma união estável ou um casamento, pois estas famílias se unem em um núcleo afetivo-sexual com uma certa duração no cotidiano. Não é imprescindível que as partes habitem sob o mesmo teto, embora este elemento seja um motivo a mais para que se enquadre em uma união estável, da mesma forma como ocorre com a relação de dependência econômica, pois existem casais que possuem suas economias separadas.

A seguir, a Figura 1, sintetiza as principais diferenças entre os institutos da união estável e da coparentalidade, que têm como ponto de interseção apenas os filhos comuns.

Figura 1 - Diferenças entre união estável e coparentalidade.

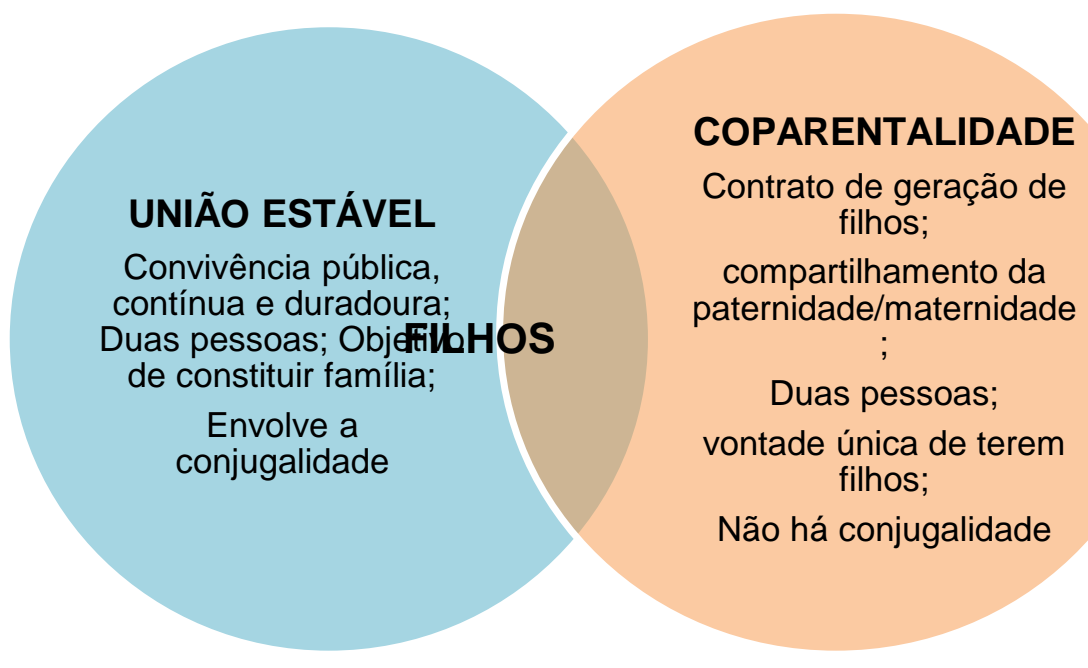

Fonte: Autoras (2021).

A principal diferença, portanto, entre o que se entende por coparentalidade e por união estável é que o primeiro está intrinsecamente ligado pela preocupação com o bem-estar da criança. Enquanto, que o relacionamento conjugal se refere à intensa preocupação com o parceiro. Nota-se um total diferença de interesse. Na coparentalidade, a figura de principal importância é a criança e/ou o adolescente. É ela quem dá ensejo para a criação dessa família. Já nos outros modelos, como o relacionamento conjugal, o foco mais relevante é o bem-estar do parceiro. A diferença consiste em que as demais relações existem independente dos filhos. Já na família coparental, os filhos são o único motivo para o surgimento dessa família.

De acordo com Albuquerque (2021), diferentemente da União estável, na coparentalidade não existe o objetivo de constituição familiar. Nesse sentido, mesmo que não haja um laço conjugal entre as partes, ambos serão responsáveis pela criação da prole, compartilharão o dever parental, guarida numa relação de afeto, com a garantia de acesso à saúde, educação e desenvolvimento moral dos filhos em comum.

Como já mencionado, o ideal é que seja firmado um "contrato de geração de filho", antes da concepção, com o objetivo de formalizar os papeis dos genitores, como registro civil da criança, convivência familiar, guarda, sustento, entre outros. Este 
contrato será fundamental para que haja margem para discussão acerca da coparentalidade, haja vista que a falta dele abrirá contendas, pois tanto a coparentalidade com a união estável pode ser vista sob o mesmo contexto pela convivência pública, contínua e duradoura. Dito isso, mesmo que as partes vivam sob o mesmo teto, não há o que se falar em união estável, pois este elemento não se configura requisito para sua formação.

Com base no exposto, surge a necessidade de uma exploração acerca do cenário envolvendo a morte do apresentador Gugu Liberato e suas nuances no que tange à seara familiarista.

Para elucidar o caso de maneira mais compreensível, serão abordadas matérias jornalísticas envolvendo toda a repercussão, em razão de serem os únicos meios de acesso disponíveis. É valoroso pontuar que esta exploração guarda o intuito de unicamente provocar reflexões e trazer alguns dados que ofereçam uma clara compreensão dos institutos em análise, uma vez que o caso envolvendo a disputa da herança, bem como o reconhecimento ou não da união estável prossegue sob segredo de justiça de acordo com o art.189 do CPC (Brasil, 2015).

O apresentador de televisão Gugu Liberato, morreu após um acidente em sua residência em Orlando, nos Estados Unidos, no dia 21 de novembro de 2019. A morte do apresentador provocou grande comoção por parte dos brasileiros além de curiosidade no que concerne à divisão de sua herança bilionária.

Nesse sentido, no dia 9 de fevereiro de 2020, o programa Fantástico exibiu uma reportagem acerca do caso que ganhou comoção nacional e grande repercussão midiática que envolve a morte de Gugu, bem como a questão polêmica que envolve a disputa que dividiu a família.

Toda essa discussão se desenrolou após apresentador não ter mencionado Rose Miriam Di Matteo como sua companheira em seu testamento, contemplando somente os filhos e os sobrinhos. Dessa forma, o embate inicia devido às contradições no que se refere ao relacionamento de Gugu e Rose, que alega ter sido companheira do apresentador durante 20 anos, e, portanto, exige sua parte da herança como a lei estabelece para aqueles que possuem união estável.

Contudo, embora todos esses anos de convivência tenham sido registrados em fotos, durante a gravidez, com os filhos pequenos, viagens, férias e cenas românticas em revistas de celebridades, não se pode simplesmente alegar que existia uma União Estável sem que antes se faça uma análise apurada e minuciosa de todo o contexto em que a família vivia.

A família Liberato enfatiza que não havia união estável entre ambos. O testamento do apresentador foi realizado em 2011 e a herança avaliada em R \$ 1 bilhão foi distribuída em 75\% dos bens para os três filhos e 25\% para os sobrinhos, além de uma pensão vitalícia para sua mãe no valor de R \$ 163 mil reais, sem a menção de Rose no testamento. Em sua defesa, Rose justifica que estava sob efeito de alguns medicamentos quando assinou o testamento e para pleitear o seu direito como companheira de Gugu, possui a finalidade de anular o documento e garantir 62,5\% da fortuna. (Batista, 2020).

É válido ressaltar que no período em que as partes firmaram o testamento não havia ainda o entendimento de declaração de inconstitucionalidade do artigo 1.790 do CC pelo STF. Dessa forma, como enfatiza Madaleno (2018), o art. 1.845 traz em seu texto que são herdeiros necessários, o convivente sobrevivente, que podia ser afastado da sucessão se o autor da herança o quisesse, na ausência de descendentes, ascendentes ou cônjuge, ou mediante a renúncia destes, podendo assim contemplar terceiros com todos os seus bens através uma cláusula testamentária ou mesmo havendo descendentes ou ascendentes, por meio de um testamento podendo dispor de sua parte inclusive para terceiros.

Nesse contexto, observa-se que o impasse mediante a possibilidade de ruptura do testamento, perante a união estável quando confirmada ou da possível exclusão do companheiro sobrevivente por disposição testamentária, pela inclusão deste como herdeiro necessário ou não, ainda renderá debates.

Essa batalha jurídica teve uma reviravolta devido à decisão provisória de pensão pleiteada por Rose ter sido derrubada na $2^{a}$ instância em consequência de um documento divulgado, que foi assinado em março de 2011 por Gugu e Rose, intitulado como "compromisso conjunto para criação de filhos". 
O documento diz que por intermédio de inseminação artificial, Gugu e Rose conceberam três filhos e os pais filiam-se por respeito e amizade, unidos tão somente como pais e que sempre habitaram em residências separadas, sendo que Gugu arcaria com todas as despesas. O registro finaliza relatando que Gugu e Rose Mirian reiteram-se totalmente realizados, cada qual mantendo e conservando, separadamente, sem qualquer participação ou interferência do outro, os seus próprios bens'

Segundo a defesa de Rose, esse documento não imobiliza o reconhecimento de União estável, pois em nenhum momento Rose denega ao direito e nem o apresentador manifesta essa renúncia. Ademais, a defesa de Rose afirma que o documento foi assinado enquanto a mesma estava em um momento de depressão profunda e que o documento foi firmado em um momento de crise do casal sendo que, por conseguinte, fizeram as pazes e acabaram se esquecendo do contrato outrora firmado.

Segundo Aguirre (2020), presidente da comissão do Direito de Família e Sucessão- OAB/SP, para se caracterizar a união estável esta tem que ser pública, duradoura e contínua, além de possuir como objetivo a constituição de família, pois a filiação por si só não comprova a existência de uma união estável.

Por outro lado, o advogado especialista em Direito de Família, Paulo Lins e Silva (2020), é resistente ao ressaltar que não existe a criação de filhos sem ter afeto e que não há essa modalidade de dois amigos criarem um filho, pois isso se configura união estável e as pessoas não possuem filhos por diversão, haja vista que não há a necessidade de viver junto e nem de haver sexo uma vez que esses fatores não desfazem a união estável. Os filhos de Gugu e Rose dizem que não compactuam com a disputa que está confrontando o último desejo do pai.

No dia 27 de setembro de 2017, outra matéria do programa de televisão Fantástico trouxe à baila mais uma polêmica no caso do apresentador, pois no processo de pedido de Green Card da família, houve uma declaração de Gugu às autoridades de imigração americana. O documento em inglês passou por uma tradução juramentada sob pena de perjúrio, no qual comunica que é parceiro da sua companheira de muitos anos, mãe de seus três filhos.

Diferentemente do Brasil, nos EUA, não existe a figura da companheira, pois não há o regime de união estável, uma vez que só existe para a lei americana o reconhecimento do casamento. Assim, há uma reflexão no sentido de não saber ao certo como será comprovada a situação tendo em vista o caso concreto e o fato de ter sido firmado em uma língua estrangeira.

Como descrito por Pereira (2020), a discussão envolvendo o apresentador se debruça em entender se a família de Gugu vai além de uma família parental, ou seja, se havia entre Gugu e Rose uma família também conjugal. Pois, a confirmação de um desses institutos muda todo o cenário patrimonial.

Em consequência, não restam dúvidas da existência de um relacionamento bastante íntimo entre Gugu Liberato e Rose Miriam Di Matteo, sobretudo no que tange à criação dos filhos, o que se contesta, no entanto, é a existência ou não de uma vida conjugal entre ambos, pois desta forma os efeitos jurídicos serão modificados para enquadrar com a realidade de cada modelo familiar. Se for confirmada a relação meramente parental, Rose Miriam Di Matteo não terá reservado os direitos sucessórios que tanto pleiteia no judiciário.

É notório que a família preenchia alguns dos requisitos indispensáveis para a configuração de uma união estável, como a durabilidade e a continuidade no tempo, uma vez que a relação perdurou por 20 anos, No entanto, não se sabe se existiu uma relação pautada no romântico-sexual, para que de fato seja caracterizada uma família conjugal. Todavia, o requisito da publicidade parece contraditório, uma vez que Gugu e Rose apareceram juntos, posando como se fossem namorados para uma famosa revista em 1994, além de Gugu já ter mencionado em seu programa de tv, ter tido um namoro com a mulher que seria mãe de seu filho.

De fato, Rose e Gugu, pareciam uma família conjugal e preenchiam alguns dos requisitos que constituem a união estável, como a publicidade que estava estampada nas capas de revistas, viagens de família e fotos de ambos como um casal.

Nas palavras de Gonçalves (2021), um dos requisitos da união estável é a sua notoriedade, como exige o art. 1.723 do CC, uma vez que além de contínua e duradoura, ela precisa ser pública, não podendo permanecer desconhecida da sociedade, 
exigindo, portanto, que os companheiros se apresentem como se fossem casados. Entretanto, é de grande relevância pontuar que em nenhum momento se nega a existência de uma família envolvendo Rose e Gugu, o que se contesta na verdade é em que modelo familiar eles viviam.

A família do apresentador afirma que não havia uma união estável, mas sim uma relação de amigos que se uniram para gerar e cuidar dos filhos em comum, o que para ser configurada necessita de um contrato, o que de fato ocorreu quando Gugu e Rose firmaram o documento em 2011, para estabelecer as regras de criação conjunta de Marina, Sofia e João Augusto.

Segundo esse contrato juntamente com o testamento que não engloba Rose, parece nítida a última vontade do de cujus que era simplesmente o intuito de constituir uma família coparental. Todavia, por ter sido uma família bastante reservada, e a vontade do apresentador somente vir à tona após o seu óbito, torna-se peculiar a sua resolução, ficando apenas para o julgador do caso, esta incumbência.

\section{Metodologia}

A pesquisa realizada neste trabalho foi de cunho bibliográfico ou de fonte secundária. A pesquisa bibliográfica é o passo inicial para a investigação e escolha de um tema relevante, auxiliando então na escolha do método mais apropriado, utilizando um olhar mais detalhado sobre o tema abordado, no qual se trata de um estudo acerca da união estável e da família coparental, trazendo uma análise sobre os pontos que diferenciam um instituto do outro. A pesquisa bibliográfica é por excelência uma fonte inesgotável de conhecimento e informações, que contribuem para a atividade acadêmica e o conhecimento geral, já que é um conjunto de conhecimentos reunidos em obras de toda natureza. Tem por finalidade específica, conduzir o leitor a pesquisar até proporcionar o saber em seu sentido mais amplo. Ela se fundamenta em vários procedimentos metodológicos, desde a leitura até o resumo e interpretação do texto, ela é a base para as demais pesquisas, pois todos os tipos de estudo devem primeiramente ter respaldo bibliográfico. Para a elaboração de uma pesquisa bibliográfica é necessário seguir os seguintes passos, como: a escolha do assunto, identificação, localização, compilação e leitura. A pesquisa compreende o levantamento de toda bibliografia já publicada, em diversos formatos, com a finalidade de proporcionar ao pesquisador o acesso a uma vasta literatura já produzida sobre determinado assunto, servindo de apoio para o desenvolvimento do trabalho científico e de análise de pesquisas.

Nesse viés, a presente abordagem se faz necessária, já que existe uma linha muito tênue que deve ser observada de acordo com o caso concreto. Além disso, o estudo dos referidos institutos do Direito de Família, serão trabalhados tendo como ponto de partida o caso do apresentador Gugu Liberato, tornando o trabalho mais didático e de fácil compreensão para a sociedade em geral.

Desta forma, para apresentar as melhores soluções possíveis para todos os problemas expostos, fez-se necessária a realização de uma pesquisa bibliográfica que de acordo com Lakatos e Marconi (2019), compreende toda a bibliografia relacionada ao assunto que já foi tornada pública, tais como: jornais, livros, revistas, artigos científicos, periódicos, material cinematográfico, meios de comunicação oral, boletins e etc., tendo a finalidade de levar o pesquisador a entrar em contato direto com tudo que foi falado, escrito ou filmado. A busca de artigos se deu nas principais bases de dados, como Google acadêmico e Periódicos da Capes. Foram utilizados como descritores para a pesquisa: coparentalidade, união estável, Gugu Liberato e Direito de Família, tendo como principais autores, Rodrigo da Cunha Pereira, Cristiano Chaves Farias, Maria Berenice Dias, Pablo Stolze, dentre outros.

Para Gil (2002 p. 44), pesquisa bibliográfica "é desenvolvida com base em material já elaborado, constituído principalmente de livros e artigos científicos a pesquisas desenvolvidas exclusivamente a partir de fontes bibliográficas". Dessa forma, a pesquisa bibliográfica pode ser um trabalho independente, tomando por base apenas as referências teóricas, as informações a serem colhidas, obtidas por meio do raciocínio, na qual se utilizará os métodos indutivo e dedutivo de forma cumulada, analisando minunciosamente cada aspecto proposto. 
Foi também fonte de informação a legislação vigente e decisões jurisprudenciais referentes ao tema objeto do estudo. Como caracteriza Severino (2020), a pesquisa bibliográfica é aquela baseada em estudos anteriores arranjadas através de doutrinas, legislação, revistas, artigos científicos, dentre outros meios de consulta. É um meio de buscar informações sistematizadas e lógicas em estudos realizados por outros autores devidamente cadastrados.

A função exercida pela pesquisa de cunho bibliográfico é apresentar ao pesquisador conhecimento direto de tudo que seja relacionado ao assunto estudado, sejam escrituras, máximas, afirmados ou debatidos, basta apenas que tenham sido anotados de alguma forma. Nesse sentido, essa pesquisa possibilitou estudos e fundamentações aprofundadas sobre a temática. Isto posto, a revisão bibliográfica é cogente para que seja demarcado um problema de investigação e, para a formação de uma ideia mais clara e precisa a respeito da situação atual do objeto estudado, bem de suas brechas.

Na visão de Medeiros e Tomasi (2020), é uma ferramenta importante na acepção dos desígnios da pesquisa científica, a revisão bibliográfica ainda coopera nas construções teóricas, nas conferições e na validação de efeitos de trabalhos de conclusão de curso e de artigos científicos.

Tais recursos permitiram compreender a magnitude do assunto e a forma como a população e as autoridades tratam o tema. Por fim, ao estudar a natureza do tema, observa-se a importância de se trabalhar com esses métodos, uma vez que trouxeram um aparato maior de dados e, consequentemente, um enriquecimento do trabalho.

\section{Considerações Finais}

Inúmeras foram as mudanças que ocorreram no conceito de família ao longo da história. Através da existência dos novos arranjos familiares as famílias patriarcais passaram a fazer menos parte da realidade social, tendo como objetivo maior o respeito à dignidade da pessoa humana, pois atualmente possibilita o pertencimento das pessoas dentro das relações que antes eram impedidas devido à força do patriarcado. Dito isso, as novas formas de famílias introduzidas no sistema brasileiro, vêm avançando no sentido de priorizar os indivíduos e criar um meio familiar saudável, em decorrência da afetividade e solidariedade.

Desse modo, as famílias passaram por grandes modificações que possibilitaram a proteção do estado perante aqueles que antes eram excluídos da tutela estatal, haja vista que o círculo familiar possuía seu objetivo inteiramente voltado para o patrimônio, tendo inclusive por muito tempo rejeitado os filhos que nasciam oriundos de relacionamentos extraconjugais ou não formalizados pelo Estado, diferenciando-os como filhos legítimos e ilegítimos, o que com o passar dos anos foram demandando posicionamentos jurisprudenciais sobre uniões não formalizadas, que culminaram na edição da súmula 380 do STF.

Atualmente, após a promulgação da CF de 1988, que traz o art. 226, ocorre o que a maioria dos doutrinadores contemporâneos denominam de "desinstitucionalização da família" e passam a enxergar o seu seio, não mais como o modelo antigo composto por um núcleo padronizado, mas sim as suas diversas mudanças que com o passar dos anos modificaram toda a realidade social.

Logo, a família matrimonial vai aos poucos deixando de ser uma regra, tornando-se somente mais uma opção dentre as inúmeras que compõem as famílias plurais. Com base nas famílias eudemonistas, os filhos já não são mais uma decorrência única e exclusiva dos relacionamentos conjugais, mas sim uma escolha pautada na afetividade entre duas pessoas que desejam constituir uma família sem que para isso ocorra uma relação romântico-sexual envolvendo as partes.

O caso do apresentador Gugu abre portas para a elucidação dos novos cenários familiares existentes, uma vez que traz consigo diversos requisitos que podem ensejar em um ou outro modelo familiar. Por um lado, há um contrato de coparentalidade e um testamento excluindo a pretensa companheira como herdeira. Por outro lado, existe a tese de inconstitucionalidade do artigo 1.790 do CC (Brasil, 2002), que equipara a companheira como mulher em casos de herança.

A família de Gugu defende que o relacionamento do apresentador com a mãe dos seus filhos era meramente fraternal, trazendo como prova a existência de um contrato como um dos requisitos que diferenciam a união estável da coparentalidade. 
Nesse contexto, para a família de Gugu, não havia um relacionamento conjugal do apresentador com Rose Miram, pois caso contrário, este não teria assinado o contrato de coparentalidade e nem teria excluído Rose de seu testamento.

Em contrapartida, a defesa de Rose alega a existência da união estável pois o relacionamento do casal preenchia todos os elementos caracterizadores de uma união conjugal, como a publicidade, continuidade, estabilidade e o objetivo de constituição de família.

O estudo sobre essa matéria foi de grande utilidade e bastante enriquecedor e teve como escopo esmiuçar as principais diferenças envolvendo a União Estável bem como o instituto da Coparentalidade no Brasil, entidade familiar hodierna, mas que ao mesmo tempo aborda uma nova perspectiva dos arranjos familiares pautados no afeto sem que para isso haja uma conjugalidade.

A relevância deste trabalho dar-se-á mediante a análise cuidadosa de todos os elementos conjecturados desses institutos, e consequente posicionamento sobre as diferenças e os requisitos de cada um trazendo como caso prático as nuances envolvendo a morte do apresentador Gugu Liberato e o modelo de família no qual o mesmo vivia. É cristalino que cada instituto possui peculiaridades que os diferencia dos demais, uma vez que sua natureza abarca elementos intrigantes e situações, como a união estável que prevê direitos para o companheiro igualado aos do casamento Civil, tendo em vista que não há hierarquização entre estes, o que causa aflições tanto para o mundo jurídico, quanto para a sociedade em geral, que se esbarrava mediante de uma afronta.

Deve-se, em primeiro plano, analisar todos os requisitos da união estável para que se possa diferenciá-la de uma possível relação parental, que é pautada na criação de uma prole sem que haja uma vida conjugal, com a existência de um contrato definindo a relação entre as partes, que trará os pressupostos para a formação da coparentalidade, como nome do(a) filho, convivência, guarda sustento além de outros detalhes.

Para fins sucessórios, é extremamente importante a definição do vínculo existente, pois caso seja uma união estável, o regime mais comum neste caso, é o da comunhão parcial de bens. A viúva será considerada meeira e não herdeira dos bens que foram adquiridos durante a união estável. Contudo, no que tange aos bens adquiridos antes da união, será considerada herdeira, em concorrência com a prole. Por outro lado, na coparentalidade, não existe meação nem a herança, uma vez que as partes não serão herdeiros um do outro, exceto se forem contemplados em testamento. Dessa forma, serão os filhos que herdarão os bens do genitor falecido. Em qualquer relação, é fundamental a celebração de um contrato, uma vez que cada vínculo possui questões patrimoniais diferentes, que se não chegarem a um consenso, poderão levar a disputas judiciais.

Portanto, é nítido o confronto existente para que se chegue a uma conclusão no caso concreto, uma vez que é muito fácil confundir a união estável com outros institutos do Direito de Família, o que acarreta grandes consequências também para o Direito Sucessório.

\section{Referências}

Ahrons, C. R. (1981). The continuing coparental relationship between divorced spouses. American Orthopsychiatric Association, 51 , $415-428$.

Albuquerque, A. (2021). Direito sucessório: diferença entre união estável e co-parentalidade. Anderson Albuquerque https://www.andersonalbuquerque.com.br/artigo\&conteudo=direito-sucessorio-diferenca-entre-uniao-estavel-e-co parentalidade\#: :text=N\%C3\%A3o\%20exi ste $\% 2 \mathrm{C} \% 20$ como $\% 20$ na $\% 20$ uni $\%$ C3\%A3o,o $\% 20$ objetivo $\% 20 \mathrm{de} \% 20$ constitui $\% \mathrm{C} 3 \% \mathrm{~A} 7 \% \mathrm{C} 3 \% \mathrm{~A} 3 \mathrm{o} \% 20 \mathrm{familiar} . \&$ text $=\mathrm{A} \% 20 \mathrm{grande} \% 20 \mathrm{diferen} \% \mathrm{C} 3 \% \mathrm{~A} 7 \mathrm{a} \%$ $20 \% \mathrm{C} 3 \%$ A $9 \% 20 \mathrm{o}, \% \mathrm{C} 3 \%$ A $9 \% 20$ essencial $\% 20$ para\%20fins $\% 20$ sucess $\%$ C $3 \%$ B 3 rios.

Azevedo, Á. V. (2019). Curso de Direito Civil: Direito de Família. (2a ed.), Saraiva Educação.

Batista Junior, J. (2020). Gugu Liberato: como foi distribuída no testamento a herança de R\$1 bi.Veja. https://veja.abril.com.br/brasil/gugu-liberato-como-foidistribuida-no-testamento-a-heranca-de-r-1-bi/.

Brasil, Senado Federal. (2017). Projeto de Lei do Senado n 394, de 2017. https://www25.senado.leg.br/web/atividade/materias/-/materia/131275.

Carvalho, D. M. de. (2020). Direito das famílias, (4a ed.), Saraiva.

Dias, M. B. (2021). Manual de Direito das Famílias. (14a ed.). 
Diniz, M. H. (2021). Curso de direito civil brasileiro. (35a ed.), Saraiva.

Engels, F. (2017). A origem da família da propriedade privada e do Estado. Lafonte.

Fantástico. Caso Gugu: novo documento põe fogo na disputa pela herança milionária do apresentador. Rio de Janeiro: Rede Globo, 17 de maio 2020. Programa de TV. https://g1.globo.com/tudo-sobre/gugu-liberato/.

Fantástico. (9 fev., 2020) "Fomos muito felizes durante esses 20 anos", afirma Rose, viúva de Gugu." Rio de Janeiro: Rede Globo. Programa de TV. https://g1.globo.com/tudo-sobre/gugu-liberato/.

Fantástico. (17 maio, 2020). "Foi uma relação baseada em muito amor”, revela suposto companheiro de Gugu” Rio de Janeiro: Rede Globo. Programa de TV. https://g1.globo.com/tudo-sobre/gugu-liberato/.

Farias, C. C., \& Rosenvald, N. (2021). Curso de direito civil: famílias (13a ed.), Ed JusPodlvm.

Figueredo, L. L. \& Figueredo, R. L. (2018). Direito Civil: famílias e sucessões. (6a ed.), Juspodivm.

Gagliano, P. S., \& Pamplona Filho, R. (2020). Manual de Direito Civil. (10a ed.), Saraiva.

Gil, A. C. (1999). Métodos e técnicas de pesquisa social. (5a ed.), Atlas.

Gomes, O. (2020). Direito de família. (14a ed.), Forense.

Gonçalves, C. R. (2021). Direito Civil Brasileiro: Direito de Família. (18a ed.), Saraiva.

Harnack. D. (2014). Co-Parenting. Reflexões acerca do compartilhamento de paternidade ou maternidade. IBDFAM. [S.I.]. Recuperado em 25 de abril, 2021, de https://ibdfam.org.br/artigos/938/CoParenting+\%E2\%80\%93+Reflex\%C3\%B5es+acerca+do+compartilhamento+de+paternidade+ou+maternidade.

Jesus, M., de et al. (2021). Manual de Direito Civil. (10a ed.), Juspodivm.

Lakatos, M. A., \& Marconi, E. M. (2019). Fundamentos de Metodologia Cientifica. (8a ed.), Atlas.

Lemos, V. (2018). Coparentalidade: brasileiros buscam parceiros para ter filhos sem relação amorosa. BBC News Brasil. Curitiba. https://www.bbc.com/portuguese/brasil-45065810.

Lôbo, P. (2020). Direito Civil-Família. (10a ed.), Saraiva.

Maluf, C. A. D., et al. (2018). Curso de direito de família. (3a ed.), Saraiva Educação SA.

Mchale, J. P., Kuersten-Hogan, R., \& Rao, N. (2004). Growings. Growing Points for Coparenting Theory and Research. Journal of Adult Development, 11(3), 221-234. https://psycnet.apa.org/record/2004-18679-006.

Medeiros, J. B., \& Tomasi, C. (2008). Comunicação científica: normas técnicas para redação científica. Atlas.

Morais, A. de. (2020). Direito Constitucional. (236a ed.), Atlas.

Morais, M. A. V. de. (2014). A Evolução do Conceito de Família no Ordenamento Jurídico Brasileiro. Recuperado em 20 de fevereiro, 2021, de http://jus.com.br/artigos/28568/a-evolucao-do-conceito-de-familia-no-ordenamento-juridico-brasileiro.

Nader, P. (2016). Curso de Direito Civil, v. 5: Direito de família. (7a ed.), Forense.

Oliveira, L. P. de. (2017). Afinal, o que é coparentalidade. https://leonardopetro.jusbrasil.com.br/artigos/481250773/afinal-o-queecoparentalidade.

Pereira, C. M. da S. (2017). Instituições de direito civil. Vol. V / Atual. Tânia da Silva Pereira. (25 ed.), Forense.

Pereira, R. C. (2017). Coparentalidade abre novas formas de estrutura familiar. https://www.conjur.com.br/2017-ago-13/processofamiliar-coparentalidadeabre-novas-formas-estrutura-familiar.

Pereira, R. da C. (2020). O contrato de geração de filhos e os novos paradigmas da família contemporânea. IBDFAM. https://ibdfam.org.br/artigos/1609/O+contrato+de+gera\%C3\%A7\%C3\%A3o+de+filhos+e+os+novos+paradigmas+da+fam $\%$ C3\%ADlia+contempor\%C3\%A2 nea.

Rosa, C. P da. (2020). Direito de Família Contemporâneo. (7a ed.), JusPODIVM.

Severino, A. J. (2007). Metodologia do trabalho científico. Cortez

Silva, J. A. (2020). Curso de direito constitucional positivo. (43a ed.), Juspodivm.

Schneider, T. (2017). Pais amigos, construindo famílias. Desconstruindo preconceitos. https://paisamigos.com/. 